\title{
Original article \\ APPRAISAL OF THE EFFICACY OF TACTILE SUBJECTIVE TEST FOR ANAESTHESIA OF THE INFERIOR DENTAL AND LINGUAL NERVES AFTER BLOCK INJECTION
}

\author{
A.E.OBIECHINA AND A.O.FASOLA \\ School of Dentistry, College of Medicine, University of Ibadan, Ibadan, NIGERIA.
}

\begin{abstract}
Tactile, verbal subjective, and objective tests were done on 300 patients after inferior dental, lingual, and buccal nerve anaesthetic block injections were given. Of the 78 patients who indicated that there was a change in the middle-third of the lower lip during tactile subjective test, $12(15.4 \%)$ had pain while $66(84.6 \%)$ had no pain when objective test was performed. Forty-two (63.6\%) out of the 66 patients (with change in the middle-third and satisfactory objective test) complained of pain when extraction was attempted. When re-injected, a change in labial sensation occurred in the mid line or beyond the midline during subsequent tactile subjective test. Adequate anaesthesia was achieved and extractions were carried out. These findings suggest that tactile subjective test is more efficient and sensitive than verbal subjective and objective tests.
\end{abstract}

KEYWORDS: Objective test; Subjective test; Local anaesthesia.

All correspondence should be addressed to: AE. Obiechina, P.O. Box 22573, University Post office, Ibadan, NIGERIA.

\section{INTRODUCTION}

Pain has been associated with dental treatment since the early days of dentistry, when dental extraction and restorations were done with crude instruments with or without adequate anaesthesia (Campbell 1970; Scott et al 1984). Kleinknecht et al (1973), Lautch (1971) and Aldosari (1996) reported that several patients who attended dental clinics were apprehensive for reasons, which include previous traumatic experience of patients, unpleasant experiences narrated by others, fear of the unknown, and anticipation of pain.

To eliminate pain, local anaesthesia had to be administered, and tests performed to determine its efficacy. In conducting subjective test after inferior dental and lingual nerves block anaesthesia, the patient was often asked to describe how the lower lip and tongue felt or to indicate if there was any change on the lower lip and tongue, on the side of injection. A positive response was usually taken as indication that anaesthesia had taken effect. This subjective test is verbal. To confirm anaesthesia however, objective test was done by applying a probe at the appropriate anatomical location while the reaction and response of the patient was noted (Howe et al, 1972).

The aim of this paper is to describe a method of tactile subjective test for anaesthesia of the inferior dental and lingual nerves after local anaesthetic block injection and to relate its efficacy to the verbal subjective and objective tests.

\section{PATIENTS AND METHODS}

Three hundred patients who needed extraction of lower mandibular molar teeth were each given local anaesthetic injection (2ml lignocaine with adrenalin 1:80000) to block the inferior dental, lingual and long buccal nerves. All the patients were seen at the Oral surgery clinic of the University College Hospital, Ibadan. Five minutes after injection, verbal subjective test was conducted by asking the patient if any change was observed in the lower lip and the tongue on the side of the injection. The response was recorded. Thereafter, tactile subjective test for anaesthesia of the inferior dental and lingual nerves was done and the result recorded.

To do the tactile subjective test of the inferior dental and lingual nerves, the patient was instructed to run the forefinger finger over the lower lip, starting from the angle of the mouth on the side of injection, and to stop the finger at any place along the lower lip where a change in sensation was observed. The place where the change in sensation occurred was noted, which indicated the extent of anaesthesia of the inferior dental nerve. For these tests, the lower lip was divided into three namely, lateral third, middle third, and the midline.

For tactile subjective test of the lingual nerve, the patient was instructed to run the tip of the tongue against the incisal edges of the upper incisors, and to indicate whether or not, there was any change in tactile sensation. A change was taken as an indication that anaesthesia extended to the terminal fibres of the lingual nerve in the tongue.

To conduct the objective test for anaesthesia of the inferior dental nerve, a probe was applied to the buccal gingiva in the region of the apex of the first mandibular premolar while observing the patient for facial expression of pain or discomfort. The patient was also asked if any sharpness was felt during the probing. Objective test for the lingual nerve was done by probing the lingual gingiva of the tooth to be extracted. The results were noted.

\section{RESULTS}

The three hundred patients consist of 147 (49.0\%) males and $153(51 \%)$ females. Their ages ranged from 15 to 71 years ( mean 33, standard deviation 14). During verbal subjective test for anesthesia of the inferior dental nerve, $279(93.0 \%)$ indicated a change of sensation in the lower lip, while 21 (7.0\%) indicated no change. Results of verbal subjective, tactile subjective, and objective tests of the inferior dental nerve are presented in Table 1.

Of the 78 patients who indicated that there was a change in the middle-third of the lower lip during tactile subjective test, 12 (15.38\%) had pain while 66 (84.6\%) had no pain when objective test was performed (Table 2 ). Forty-two $(63.6 \%)$ out of the 66 patients (with change in 
the middle-third and satisfactory objective test) complained of pain when extraction was attempted. The patients located the pain as originating from within the bone. They were re-injected and during subsequent tactile subjective test, a change in labial sensation occurred in the midline or beyond the midline. Adequate anaesthesia was achieved and extractions were carried out. The $8(2.7 \%)$ patients who had no change or a change in the lateral third of the lower lip experienced pain during objective tests.

The result of the verbal subjective, tactile subjective and objective tests of the lingual nerve are presented in Table 3. The result showed a marginal increase in tactile subjective test over verbal subjective test.

TABLE 1:

TEST FOR ANAESTHESIA OF THE LOWER LIP AND INFERIOR DENTAL NERVE $(\mathrm{N}=300)$

\begin{tabular}{lll}
\hline $\begin{array}{l}\text { Verbal } \\
\text { Subjective } \\
\text { Test }\end{array}$ & Tactile Subjective Test & $\begin{array}{l}\text { Objective } \\
\text { Test }\end{array}$ \\
\hline $\begin{array}{l}\text { Change } \\
279(93.0 \%)\end{array}$ & $\begin{array}{l}\text { Change in the midline or } \\
\text { across the midline } \\
\text { 214 }(71.3 \%)\end{array}$ & $\begin{array}{l}\text { No pain } \\
226 \\
(75.3 \%)\end{array}$ \\
\hline $\begin{array}{ll}\text { No Change } \\
21(7.0 \%)\end{array}$ & $\begin{array}{l}\text { Change in the middle- third } \\
\end{array}$ & $\begin{array}{l}\text { Pain } \\
78(26.0 \%)\end{array}$ \\
& & $(24.7 \%)$ \\
\hline
\end{tabular}

No change or change in the lateral-third

$8(2.7 \%)$

Table 2:

Distribution of pain during objective Test and tooth extraction, in patients who experienced change of sensation in the middle third of the lower lip during tactile subjective test $(\mathrm{N}=78)$

\begin{tabular}{llll}
\hline & Pain & No pain & Total \\
\hline $\begin{array}{l}\text { Objective } \\
\text { test }\end{array}$ & $12(15.4 \%)$ & $66(84.6 \%)$ & 78 \\
\hline $\begin{array}{l}\text { Tooth } \\
\text { extraction }\end{array}$ & $54(69.2 \%)$ & $24(30.8 \%)$ & 78 \\
\hline
\end{tabular}

Table 3:

Test for anaesthesia of the tongue and lingual Nerve. $(\mathrm{N}=300)$

\begin{tabular}{|l|l|l|}
\hline $\begin{array}{l}\mathbf{N}=300) \\
\text { Verbal Subjective } \\
\text { Test }\end{array}$ & $\begin{array}{l}\text { Tactile Subjective } \\
\text { Test }\end{array}$ & $\begin{array}{l}\text { Objective } \\
\text { Test }\end{array}$ \\
\hline Change & Change & No pain \\
$263(87.7 \%)$ & $272(90.3 \%)$ & 289 \\
& & $(96.3 \%)$ \\
\hline & & \\
No change & No change & Pain \\
$37(12.7 \%)$ & $28(9.3 \%)$ & $11(3.75 \%)$ \\
\hline
\end{tabular}

\section{DISCUSSION}

Patients attending dental clinics are often worried about pain. Efforts have been made to reduce to the barest and possibly eliminate pain totally. Several ways of achieving anaesthesia have been introduced. These include acupuncture ( $\mathrm{Gu}$ et al, 1985), transcutaneous electrical nerve stimulation (Wilder-Smith et al, 1989), computer-assisted injection of local anaesthetics (Friedman et al, 1997), and electronic dental anaesthesia (Yap et al, 1996; Burke 1997). However, these innovations have their limitations and are not very readily available. The injection of local anaesthetics with needle and syringe, and testing for anaesthesia still prominent in dentistry.

It is worthy of note that $214(71.3 \%)$ of the patients had a change in sensation in the mdline or across the midline of the lower lip during the tactile subjective test, 279 $(93.0 \%)$ had change of sensation in the lower lip during verbal subjective test, and $226(75.3 \%)$ had no pain during objective test (Table 1). Those who observed change of sensation in the midline or beyond the midline of the lower lip, had no pain when objective test for anaesthesia of the inferior dental nerve was done. Furthermore, 42 (18.6\%) out of the 226 patients who had no pain during the subjective test, had pain when extraction was attempted. Adequate anaesthesia was achieved when they were reinjected and tactile subjective test showed a change of sensation in the midline of the lower lip and across the midline. This finding is significant and suggests that tactile subjective test is more sensitive and efficient than verbal subjective and objective tests. Therefore, a change of sensation along the middle third of the lower lip could be taken as an indication that the inferior dental nerve was not adequately anaesthetised, while a change along the midline and beyond, would indicate that anaesthesia was adequate. Inability to obtain a change of sensation in the midline of the lower lip could be attributed to failure to deposit anaesthetic solution close to sufficiently perfuse the inferior dental nerve. That the result obtained from tactile subjective test was better than verbal subjective, and objective tests could be explained by the fact that tactile subjective test determined the extent and effect of anaesthesia in the terminal fibres of the nerves, in contrast to verbal subjective, and objective tests.

Thus patients that showed no change or change of sensation in the lateral third of the lower lip need not be subjected to the trauma of objective testing with a probe. Such a response should be regarded as indicative of ineffective or inadequate anaesthesia of the inferior dental nerve, while a change of sensation at the midline and beyond should be indicative of effective anaesthesia and objective test could be confidently performed. This study further suggests that while a change in sensation extending to the middle third of the lower lip indicates that anaesthesia has taken effect, it is inadequate for tooth extraction. In such situations therefore, we suggest that inferior dental nerve block be repeated. This measure would save the patient from pain arising from inadequate anaesthesia. These findings provide useful check for dental students who inject local anaesthetics to the inferior dental nerve.

Although a marginal difference was noted between tactile subjective test and verbal subjective test of the lingual nerve, this study revealed that verbal subjective test was unable to precisely identify the extent of anaesthesia.

Bourgoyne (1989) and Matthews et al, (1997) reported that fear, anxiety and pain diminished when local 
anaesthetic injection was precisely and effectively administered. Tactile subjective test provides a way of eliminating trauma arising from ineffective and inadequate anaesthesia during objective tests and operative procedures. It should also be considered beneficial in reducing fear and anxiety associated with dental treatment.

\section{REFERENCES}

Aldosari A.M. (1996). Dental fear among visitors of primary health care centres in Saudi Arabia. Odonto-Stomologie Tropacale, 76, 4-7.

Bourgoyne R. (1989). Anaesthetic steps stop fear. Dentist, 67, 35-46.

Burke F.J. (1997). Dentist and patient evaluation of an electronic dental analgesia system for controlling discomfort of injections. Dental Update, 24, 154-157.

Campbell J.M. (1970). An outline of dental history. Br. Dent J, 126, 523-527.

Friedman M.J., Hochman M.N. (1997). A $21^{\text {st }}$ century computerised injection system for local pain control. Compendium of continuing education in dentistry (Jamesburg, NJ), 18, 995-100.
Gu Z.Q., Wang Y.Q., Yin Y.X., Yu M.H., Wang H.J., Chen W.M. (1985). Clinical research on tooth extraction under acupuncture anaesthesia. Acta Academiae Medicinae Wuhan, 5, 225-230.

Howe G.L., Whitehead H. (1975). Local anaesthesia in dentistry. Ch VI, pp34. John Wright \& Sons Ltd, Bristol.

Kleinknecht R.A., Klepac R.K., Alexander L.D. (1973). Origin and characteristics of fear in dentistry. JADA, 86, 842-848.

Lautch H. (1971). Dental phobia. Br. J. Psychiatry, 119, 151-158. Matthews R., Ball R., Goodly A., Lenton J., Riley C., Sanderson S., Singleton E. (1997). The efficacy of local anaesthesia administered by general dental practitioners. $\mathrm{Br}$. Dent J, 182, 175-178.

Scott D.S., Hirschman R., Schroder K. (1984). Historical antecedents of dental anxiety. JADA, 108, 42-45.

Wilder-Smith P., Zimmermann M. (1989). Analgesia by transcutaneous electrical nerve stimulation (TENS). Schweizer Monatsschrift fur Zahnmedizin (German), 99, 653-657.

Yap A.U. Ong G. (1996). An introduction to electronic anaesthesia. Quintessence International, 27, 325-31.

Received: June 2001

Accepted: August 2001 
